behind other branches of science in taking advantage of improved methods of research and in establishing itself upon the sound basis of faots, demonstrated by experiment and observation with instruments of precision.

What has been said will also show that there is no room for creeds and pathies in medicine, any more than in astronomy, geology or botany. Every man is entitled to his own opinion upon any unsettled problem, but if he entertains an opinion in conflict with ascertained facts he simply shows his ignorance. There is no restriction placed upon any physician who graduates from our regular schools as to the mode of treatment he should pursue in any given case. If he sees fit to prescribe a bread pill or a hundredth trituration of carbo vegetabilis there is no professional rule of ethics to prevent him from doing so. But if his patient dies from diphtheria because of his failure to administer a proper remedy, or if he recklessly infects a wound with dirty fingers or instruments, or transfers pathogenic streptococci from a case of phlegmonous erysipelas to the interior of the uterus of a puerperal woman, it would appear that the courts should have something to say as to his fitness to practice medicine. There is, however, nothing in the code of ethics which will prevent him from associating with reputable practitioners. But no matter where or when he obtained his medical degree, he can scarcely be said to belong to the modern school of scientific medicine. We must not fail to recognize, however, that the progress of knowledge has been so rapid that it is impossible for the busy practitioner to keep pace with it, and that even the requirement now generally adopted by our leading medical schools, for a four years' course of study, is inadequate for the attainment of such a degree of professional knowledge and practical skill in diagnosis and therapeutics as is desirable for one who intends to practice scientific medicine.

\section{UNIFORMITY THE KEY TO RECIPROCITY.}

Presidential Address to the National Confederation of State Medical Examining and Licensing Boards, eighth annual meeting, held at Denver, Colorado, June 6, 1898.

BY WILLIAM WARREN POTTER, M.D.

BUFFALO, N. Y.

The members of this Confederation are entitled to receive the thanks of the communities which they represent upon the substantial progress that is making all over the Union toward a more perfect system of medical education. It is believed that these improvements have been due in a large measure to the influ. ence exercised by State medical examining boards. It has been my privilege on previous occasions when addressing this body to refer to the relationship between the medical schools and the State examining boards, and I hope I may be pardoned for again call. ing special attention to this subject, which I regard of much importance.

Before entering into its extended discussion, how. ever, let me remark that it is a significant fact that no medical journal or magazine of influence anywhere in the United States has uttered a word of antagonism to the system of separate examination by the State, a practice which is fast becoming prevalent in all the States and Territories. If a few of doubtful standing have endeavored to create dissension, or have expressed opposition to the method, they have found no listeners, or at least they have not been able to impress their readers with their sincerity or the justice of their wail.

Society papers, too, have been devoid of adverse criticism except, perhaps, in a few unimportant instances. There was a time when considerable criticism was directed toward the character of the examinations, especially at the questions propounded; but as the conditions have been more and more appreciated we observe less complaint of this kind. It has been stated that only teachers in the schools could adequately examine for the State. However much this might appear good in theory, in practice its fallacy has been demonstrated. Only theorists now venture to affirm or reaffirm this now exploded sophism.

No one will. I believe, asseverate that the state examinations are perfect, for there is still much room for improvement; but the work may well be left in the hands of the examiners, who may be intrusted with it with every confidence that they will address themselves to its faithful and honest prosecution.

The colleges have now agreed by a considerable majority that four years is the proper time to set apart to medical training. Not a few are of the opinion that nine months in each year should be devoted to college work. Perhaps all will soon come to this conclusion. The two important questions remaining to be next settled are: 1 , uniformity in preliminaries, and 2, equalization of State examination. The first concerns the colleges, the last the examiners must attempt to solve.

By far the most important of the two is the one relating to preliminary qualifications requisite to entitle a neophite to enter upon the study of medicine. If all medical colleges could agree upon a uni. form minimum it would not be long before other moot questions would be settled, even to the interstate indorsement of licenses.

The difficulties in the way are chiefly of degree; for none question, so far as I know, the necessity of some literacy before accepting matriculates. In the East the tendency is toward higher preliminaries than in the West and South. Our Southern friends contend that good doctors can be made with less education than would satisfy our Eastern ideals; that in the mountainous regions not so much of letters as of sense is demanded; that highly educated men will not settle in those districts, hence the people will suffer for want of medical service; and that for these and other reasons not only must they be permitted to accept students with a low grade of educational attainments, but that also they must be allowed to grad. uate them in medicine after shorter terms of collegiate training. This on its face seems reasonable and is convincing to many; at least it appears to satisfy the consciences of many college professors. It is not an argument, however, that would hold for a moment if all the colleges were endowed. It is difficult to overcome it so long as incomes depend upon numbers in attendance. It has, however, been the experience of schools that have adopted high preliminaries, that the more intelligent students are attracted to their amphitheaters; that a more satisfactory quality of instruction can be imparted; that less time is required in primitive work and that broader training is the result.

It is a mistake to suppose that students will flock to low grade schools. They almost invariably search for the best and will not be satisfied with less. It is 
a quality of the American character to surmount obstacles and to triumph over difficulties. This is as true in relation to medicine as in other affairs of life. If medicine is made easily it is not highly prized nor does it command respect. Cheap articles are of little value and are soon wasted. So a professional diploma easily obtained and bestowed upon the illiterate is tossed about or treated with indifference.

It is difficult to understand why there should be opposition to a reasonable elevation of preliminary requirements by any college of pride or standing. Is it unreasonable to say that no candidate should be admitted to matriculate who does not at least possess such acquirements as are demanded of a high school graduate? Surely no experienced teacher could reasonably object to such a standard as a minimum requirement.

Let us see if it works an injustice to the student. I have yet to meet a physician of a few years experience in practice who was deficient in his English education who did not regret the fact. Many have blamed the colleges for accepting them without proper preliminary acquirements. A very large group of this class begin to feel chagrin before their medical training advances very far. They mingle with other students well trained in their preliminaries and are not slow to recognize the immense advantage possessed by such, and to keenly feel their own incompetency. A few, perhaps, are indifferent to such accomplishments, but these generally hire themselves to a medical grocer who deals out his cure-alls by the gallon and advertises a medical staff of attendants with the illusory addendum-consultations free. Or, perhaps they employ a team of horses and a wagon and go about the country auctioneering their wares in sad English and with sadder morals.

Thoughtful men who enter medicine always feel regret when their early education has been neglected and they are quite inclined to blame the colleges for accepting them under such conditions. It would seem, therefore, a kindness to the students themselves to establish such a minimum standard of preliminaries as will make men self-respecting, as well as conduce to an appreciation of the dignity of the profession of medicine.

It seems to me that it has already been clearly demonstrated that neither teachers nor pupils are satisfied with anything less than a reasonable preliminary educational standard. It is true that some college professors are not yet aroused to the real necessities that are presenting on this question; indeed, they in a few instances are inclined to ridicule any attempt to make things better. But such men are more to be pitied than to be condemned. They form the small minority that is constantly growing beautifully less. They sometimes display their oratory in debate or their facile pens in the magazines, but beyond a momentary applause they get very little recognition and still less approbation. I wish all such could have heard Dr. Holland, the distinguished president of the College Association, when he addressed this Confeder. ation last year. It seems to me that his convincing words would have forever silenced opposition to the principles involved in the reforms we are seeking to establish.

In turning to the problem of equalizing or standardizing the State examinations we find a field for serious and ample thought. If we ask the colleges to adopt a uniform standard as to time, four years' courses of nine months each, and similar methods of instruction in laboratory and clinical work, is it not fair to them that we, ourselves, should establish a similarity of methods in conducting the State examinations? Is it not fair to teachers and candidates for State license that we shall foreshadow the general lines of our examination by a properly prepared syllabus and by modeling our questions upon the modern methods of teaching? Should we not in all the States also have similar examination tests, such as a uniform number of questions in each of the principal divisions of medical science, and a uniform period of time for conducting the examinations? These are some of the questions that are first presented in an inquiry of this kind. One of the most absorbing questions connected with State examinations is that of reciprocity of licensure. When it is ascertained that physicians licensed by any one State can not commence practice in another State without submitting again to an examination, it naturally provokes criticism against the system. Sometimes this criticism becomes angry and defiant, and examining boards are condemned as being responsible for a faulty system.

Thoughtful men will, however, easily understand how unfair it would be to accept licenses indiscriminately by States having high standards. The pathway to reciprocity consists in establishing not only uniformity of methods of teaching, but similarity in systems of examination by the several States. Just as soon as colleges can agree upon a minimum standard of requirements, the examiners must turn their attention to standardizing their work. I hope much progress will be made this present session of the Confederation in bringing about the former. When this is accomplished it will be in order for a committee to be created by this body, probably to consist of one member from each State and Territory represented in it, whose province shall be to take into consideration the propriety of standardizing the examinations.

It is not my purpose at this time to enter into a discussion of the details of this important subject, but rather to invite attention to it in the expectations that some thought will be bestowed upon it that will lead to a clearer conception of the way and manner it should be dealt with when it comes up for consideration. Some reference was made to it in my annual address last year. I wish to accentuate what I then said on the subject, and to invite your serious attention to this most important and essential duty.

ADDRESS.
Lresidential Address delivered before the Arkansas Medical society,
Little Rock, Ark.
A. J. VANCE, M.D.
HARrison, ARk.
Today treasure-laden memory brings before me as
an ever-changing kaleidoscope the faces of the men
who have stood as I stand today before this honora-
ble body. Some are still with us giving their ener-
gies and intellects to the up.building of our profession.
Others have crossed over and are resting from the
toil and heat of the day. Not only the faces of the
men who have preceded me for the fifteen years I
have known this society, but many of their thoughts
found an abiding place in my search for medical
knowledge, that have often been of great benefit.to me.
It is not my object to speak today of the recent
developments that have been made in the world of

